\title{
A review towards finding a simplified approach for modelling the kinetics of the soluble microbial products (SMP) in an integrated mathematical model of membrane bioreactor (MBR)
}

\author{
M.F.R. Zuthi ${ }^{a}$, H.H. Ngo ${ }^{a, \star}$, W.S. Guo ${ }^{a}$, J. Zhang ${ }^{b}$, S. Liang ${ }^{b}$ \\ ${ }^{a}$ Centre for Technology in Water and Wastewater, School of Civil and Environmental Engineering, University of Technology Sydney, Sydney, NSW 2007, \\ Australia \\ b Shandong Provincial Key Laboratory of Water Pollution Control and Resource Reuse, School of Environmental Science and \\ Engineering, Shandong University, Jinan 250100, China
}

Keywords: Soluble microbial product; Activated sludge model; Membrane bioreactor; Mathematical model

\begin{abstract}
Soluble microbial products (SMPs) tend to accumulate in the membrane bioreactor (MBR) systems as a consequence of high membrane rejection and apparently low biodegradability within the wastewater treatment system. The extension of the activated sludge models (ASMs) with SMPs, therefore, has received crucial importance in recent days, particularly considering their potential use as indicators of the membrane fouling propensity. This paper presents a critical review of the formation and degradation kinetics of SMP subdivisions that have so far been used for the mathematical modelling of MBR. The paper identified a simplified approach to incorporate the kinetics of the SMP formation and degradation in the general mathematical models of MBR. It suggested that the inclusion of only four additional linear differential equations in the ASM1-SMP integrated mathematical model could simulate well the effluent quality and membrane fouling prediction. The model would also serve as a useful tool in optimizing operation conditions for better treatability and fouling control.
\end{abstract}




\section{Introduction}

Membrane fouling and its control has become a major concern for the sustainable and economically feasible operation of the membrane bioreactor (MBR) system as it greatly hinders the sys- tem's efficiency for better effluent quality with lower sludge pro- duction. The presence of soluble microbial products (SMPs) has great significance to the studies of membrane fouling since the membrane rejection mechanism was identified as dependent on the rate of the SMP loading. Many studies recognized SMPs as one of the major contributors of the membrane fouling (inter alia Rosenberger et al., 2005, 2006; Liang et al., 2007; Drews et al., 2008; Kimura et al., 2009; Meng et al., 2009). The understanding of the SMP kinetics including its characterization, therefore, war- rants a more careful consideration through mathematical model- ling studies for a better understanding of its influences on the bioprocesses and membrane fouling mechanism.

Since the late eighties, many researchers recognized that the SMPs could play an important role in the biological wastewater treatment system.

* Corresponding author. Tel.: p61 2 95142745; fax: p61 295142633. E-mail address: h.ngo@uts.edu.au (H.H. Ngo).
Namkung and Rittmann (1986) subdivided SMPs into utilization-associated products (UAP) and biomassassociated products (BAP), and till date these are the widely accepted sub- divisions of SMP. UAPs are produced from the substrate degrada- tion only but BAPs are assumed to be produced by the decay of the active biomass (Namkung and Rittmann, 1986; Furumai and Rittmann, 1992) or by the hydrolysis of bound extracellular poly- meric substances (EPS) (Laspidou and Rittmann, 2002a,b) or by the combination of both (Aquino and Stuckey, 2008). Due to the high membrane fouling potential of SMPs, mathematical models have been developed introducing these kinetics into the bioprocess of MBR either separately (de Silva et al., 1998) or with the extension of basic Activated sludge models (ASMs) (Lu et al., 2001; Oliveira- Esquerre et al., 2006; Jiang et al., 2008). As the physical mecha- nism of the membrane plays a vital role in describing the mem- brane fouling of MBR, ASMs-SMP models have also been integrated with the resistance-in-series models in various forms (inter alia Lee et al., 2002; Di Bella et al., 2008; Mannina et al., 2011; Mannina and Di Bella, 2012). However, the integration of the SMP kinetics into the basic ASMs has greatly complicated the tasks of the mathe- matical modelling, particularly due to some additional process parameters measurement of which proved to be unfeasible for practical applications. 


\begin{tabular}{|c|c|c|c|}
\hline \multicolumn{2}{|c|}{ Nomenclature } & \multirow{3}{*}{$\begin{array}{l}\mathrm{Q} \\
\mathrm{R}_{\mathrm{dc}} \\
\mathrm{R}_{\mathrm{m}}\end{array}$} & \multirow{3}{*}{$\begin{array}{l}\text { Influent flow rate } \\
\text { Resistance of the dynamic sludge film } \\
\text { Intrinsic resistance of the membrane }\end{array}$} \\
\hline & & & \\
\hline a & Empirical constant & & \\
\hline AOB & Ammonia oxidizing bacteria & $\mathrm{R}_{\mathrm{p}}$ & Pore fouling resistance \\
\hline ASM & Activated sludge model & $\mathrm{R}_{\mathrm{sc}}$ & Resistance of the stable sludge cake layer \\
\hline b & Empirical constant & $\mathrm{R}_{\mathrm{T}}$ & Overall filtration resistance \\
\hline BAP & Biomass associated products & $\mathrm{R}_{\text {tot }}$ & Total resistance \\
\hline $\mathrm{b}_{\mathrm{A}}$ & Decay rate coefficient for autotrophy & $\mathrm{R}_{\mathrm{TS}}$ & Filtration resistance for one section \\
\hline $\mathrm{b}_{\mathrm{BAP}, \mathrm{A}}$ & Autotrophic decay co-efficient for formation of BAP & $\mathrm{r}_{\mathrm{p}}$ & Specific pore fouling resistance in terms of the filtrate \\
\hline $\mathrm{b}_{\mathrm{BAP}, \mathrm{H}}$ & Heterotrophic decay co-efficient for formation of BAP & & volume \\
\hline$b_{H}$ & Decay rate coefficient for heterotrophy & $r_{\mathrm{dc}}$ & Specific filtration resistance of the dynamic sludge film \\
\hline $\mathrm{b}_{\mathrm{STO}}$ & Decay rate coefficient for storage material & $\mathrm{r}_{\mathrm{BAP}}$ & Rate of BAP production \\
\hline c & Empirical constant & $\mathrm{r}_{\mathrm{h}, \mathrm{BAP}}$ & Degradation rate of BAP \\
\hline COD & Chemical oxygen demand & $\mathrm{r}_{\mathrm{h}, \mathrm{UAP}}$ & Degradation rate of UAP \\
\hline $\begin{array}{l}\mathrm{COD}_{\text {perm }} \\
\mathrm{d}\end{array}$ & $\begin{array}{l}\text { COD in the permeate } \\
\text { empirical constant }\end{array}$ & $\mathrm{r}_{\mathrm{sc}}$ & $\begin{array}{l}\text { Specific filtration resistance of the stable sludge cake } \\
\text { layer }\end{array}$ \\
\hline DO & Dissolved oxygen & rUAP & Rate of UAP production \\
\hline EPS & Extracellular polymeric substances & $\mathrm{S}$ & Substrate concentration in bioreactor \\
\hline $\mathrm{F} / \mathrm{M}$ & Food to microorganism ratio & $\mathrm{S}_{\mathrm{i}}$ & Influent substrate concentration \\
\hline$f_{\text {BAP }}$ & Fraction of BAP produced during cell lysis & $\mathrm{S}_{\mathrm{ALK}}$ & Alkalinity of the wastewater \\
\hline$f_{\text {UAP }}$ & Fraction of UAP produced during substrate uptake & $\mathrm{S}_{\mathrm{BAP}}$ & BAP (COD units) \\
\hline$f_{S i}$ & Fraction of soluble inert COD in COD influent & $\mathrm{S}_{\mathrm{NH}}$ & Ammonium plus ammonia nitrogen concentration \\
\hline $\mathrm{f}_{\mathrm{s}}$ & Substrate fraction below critical molecular weight in & $\mathrm{S}_{\mathrm{o}}$ & Dissolved oxygen concentration \\
\hline & bioreactor & $\mathrm{S}_{\mathrm{s}}$ & Readily biodegradable organic substrates \\
\hline$i_{x, p}$ & Ammonia fraction in particulate products & SMP & Soluble microbial products \\
\hline $\mathrm{J}$ & Local filtration flux trough the i-th membrane section & $\mathrm{SMP}_{\text {cak }}$ & mem SMP concentration at cake layeremembrane \\
\hline & Overall flux & & interface \\
\hline $\mathrm{K}_{\mathrm{ALK}}$ & Half-saturation coefficient for alkalinity & $\mathrm{SMP}_{\text {per }}$ & eate SMP concentration in the permeate \\
\hline $\mathrm{K}_{\mathrm{BAP}}$ & Biomass affinity constant for BAP & $\mathrm{SMP}_{\text {reac }}$ & SMP concentration in the reactor \\
\hline $\mathrm{K}_{\mathrm{NH}, \mathrm{H}}$ & Nitrogen affinity constant for heterotrophy & $\mathrm{S}_{\mathrm{NO}}$ & Nitrate plus nitrite nitrogen \\
\hline $\mathrm{K}_{\mathrm{NO}}$ & Nitrate half-saturation coefficient for autotrophic & $\mathrm{S}_{\mathrm{O}}$ & Oxygen \\
\hline & biomass & SRT & Solid retention time \\
\hline $\mathrm{K}_{\mathrm{OH}}$ & Dissolve oxygen affinity constant & $\mathrm{S}_{\mathrm{SMP}}$ & Total soluble microbial product \\
\hline $\mathrm{K}_{\mathrm{O}, \mathrm{H}}$ & Oxygen half-saturation coefficient for heterotrophic & $\mathrm{S}_{\text {UAP }}$ & UAP (COD units) \\
\hline & biomass & $t_{\mathrm{f}}$ & Filtration time \\
\hline Ksto & Biomass affinity constant & TMP & Transmembrane pressure \\
\hline $\mathrm{K}_{\text {UAP }}$ & UAP affinity constant & $\mathrm{TMP}^{\mathrm{P}}$ & Transmembrane pressure coefficient \\
\hline $\mathrm{k}_{\mathrm{h}, \mathrm{BAP}}$ & Hydrolysis rate for BAP & UAP & Utilization associated products \\
\hline $\mathrm{k}_{\mathrm{h}, \mathrm{UAP}}$ & Hydrolysis rate for UAP & $\mathrm{V}$ & Volume of bioreactor \\
\hline $\mathrm{K}_{\mathrm{s}}$ & Substrate affinity constant & $\mathrm{X}_{\mathrm{a}} / \mathrm{X}_{\mathrm{A}}$ & Concentration of active cell \\
\hline $\mathrm{K}_{\mathrm{SMP}}$ & SMP half-saturation coefficient for heterotrophic & $\mathrm{X}_{\mathrm{B}, \mathrm{A}}$ & Active autotrophic biomass \\
\hline & biomass & $\mathrm{X}_{\mathrm{B}, \mathrm{H}}$ & Active heterotrophic biomass \\
\hline LC-OCD & Liquid chromatography- organic carbon detection & $\mathrm{X}_{\mathrm{H}}$ & Heterotrophic biomass concentration (mgCOD/L) \\
\hline MBR & Membrane bioreactor & $\mathrm{X}_{\mathrm{STO}}$ & Cell internal storage product of heterotrophic biomass \\
\hline $\mathbf{M}_{\mathrm{dc}}$ & sludge mass in the dynamic sludge film & & $(\mathrm{mgCOD} / \mathrm{L})$ \\
\hline MFI & Modified fouling index & $\mathrm{X}_{\mathrm{TSS}}$ & Total suspended solids in the wastewater \\
\hline $\mathrm{MFI}_{\mathrm{MBR}}$ & MFI in the MBR & $\mathrm{Y}_{\mathrm{a}}$ & Autotrophic yield coefficient \\
\hline $\mathrm{MFI}_{\text {sol }}$ & MFI for soluble materials & $\mathrm{Y}_{\mathrm{H}}$ & Heterotrophic yield coefficient \\
\hline $\mathrm{MFI}_{\mathrm{ss}}$ & MFI for suspended solids & $\mathrm{Y}_{\mathrm{SMP}}$ & Heterotrophic yield coefficient from SMP \\
\hline MLSS & Mixed liquor suspended solids & $\mathrm{g}_{\mathrm{UAP}, \mathrm{H}}$ & UAP formation constant of heterotrophs \\
\hline MP & Microbial products & $\mathrm{g}_{\mathrm{UAP}, \mathrm{A}}$ & UAP formation constant of autotrophs \\
\hline $\mathrm{M}_{\mathrm{sc}}$ & Sludge mass in the stable sludge cake attached to the & $\mathrm{g}_{\mathrm{UAP}, \mathrm{H}}$ & Fraction of UAP produced during heterotrophy growth \\
\hline & membrane & $\mathrm{m}_{\mathrm{SMP}}$ & Maximum specific growth rate of SMP for heterotrophs \\
\hline MW & Molecular weight & g & Correction factor for anoxic growth of heterotrophs \\
\hline $\mathrm{N}$ & Nitrogen & $\mathrm{m}$ & Viscosity of permeate \\
\hline $\mathrm{NH}_{4}$ & Ammonium & $\mathrm{m}_{\mathrm{H}, \mathrm{S}}$ & Maximum growth rate of heterotrophy on $\mathrm{S}_{\mathrm{s}}$ \\
\hline $\mathrm{NO}_{3}$ & Nitrate & $\mathrm{m}_{\mathrm{H}, \mathrm{STO}}$ & Maximum growth rate of heterotrophy on $\mathrm{X}_{\mathrm{STO}}$ \\
\hline NOB & Nitrite-oxidizing bacteria & b & Soluble MFI coefficient \\
\hline PS & Polysaccharide & g & Suspended solids MFI coefficient \\
\hline
\end{tabular}


The review done in this paper is aimed at discussing the stateof-the-art in this field of research along with identifying the limitations of different approaches. The main aim of the paper is to find out a simplified approach for the inclusion of SMP kinetics into an integrated mathematical model of ASM without sacrificing the accuracy of the prediction of state variables of the base ASM models. A modified Lu's model has been suggested at the end of the paper. The model is recommended to be integrated with the available cake resistance models to capture the membrane fouling phenomena of MBR.

\section{Formation and degradation kinetics of SMP}

SMPs are usually defined as the group of soluble organic compounds that are released in the solution due to microbial metabolism in the wastewater treatment. Substrate degradation, biomass decay and hydrolysis of extracellular polymeric substances (EPSs) are the major processes identified for their formation and degradation. It has been reported that the heterotrophs (more than $92 \%$ ) are mainly responsible for the production of SMP while the SMP produced by the autotrophs contribute to less than $8 \%$ of the total SMP (Xie et al., 2012). The fraction of autotrophs was attributed to the ammonia-oxidizing bacteria (AOB-5\%) and the nitriteoxidizing bacteria (NOB-3\%).

The utilization associated products of the SMPs i.e. the UAPs are generally classified as compounds produced during substrate metabolism at a rate proportional to the rate of substrate degradation (Namkung and Rittmann, 1986; Laspidou and Rittmann, 2002b; Aquino and Stuckey, 2008). Jiang et al. (2008) performed detailed characterisation of UAP using LC-OCD and then hypothesized about two types of UAP based on the molecular weight (MW) and their biodegradability. The UAPs produced during storage phase of readily biodegradable substrate have a lower MW and are biodegradable, and the UAPs produced during the utilization of storage products have a higher $\mathrm{MW}$ and are probably more refractory. Unlike UAPs, there exist ambiguous concepts for describing the production mechanism of the BAPs. It was assumed in earlier studies that BAPs are produced from the decay of active biomass (Namkung and Rittmann, 1986; Furumai and Rittmann, 1992; de Silva and Rittmann, 2000). Laspidou and Rittmann (2002a, 2002b) clearly differentiated the active biomass into active cells and bound (floc-associated) EPS that were hydrolysed to form BAP. However, Ramesh et al. (2006) compared the physicochemical characteristics of hydrolysed EPS and BAPs but found them non-identical in all properties. Later, Aquino and Stuckey (2008) followed the same concept of active biomass differentiation given by Laspidou and Rittmann (2002b) but added the decay of active cells for BAP production on top of the hydrolysis of the bound EPS. However, the researchers have come to a general consensus that both the UAP and BAP are biodegradable and thus cycle back to become substrate cells.

Following the above discussions, three main concepts for the SMP formation and degradation can be differentiated as shown in Fig. 1. Menniti and Morgenroth (2010) compared three conceptual models (de Silva and Rittmann, 2000; Laspidou and Rittmann, 2002a; Aquino and Stuckey, 2008) which were developed based on the above mentioned concepts. The objective of the study was to justify their ability to predict SMP concentrations observed in an MBR system during a period of increased SMP and bound EPS production due to increased predation. Each of the conceptual models could capture the steady-state data reasonably well. However, only the conceptual model of the Aquino and Stuckey (2008) was able to reproduce system performance under dynamic operating conditions while the other two models were unsuccessful to do the same. The structure of the model proposed by
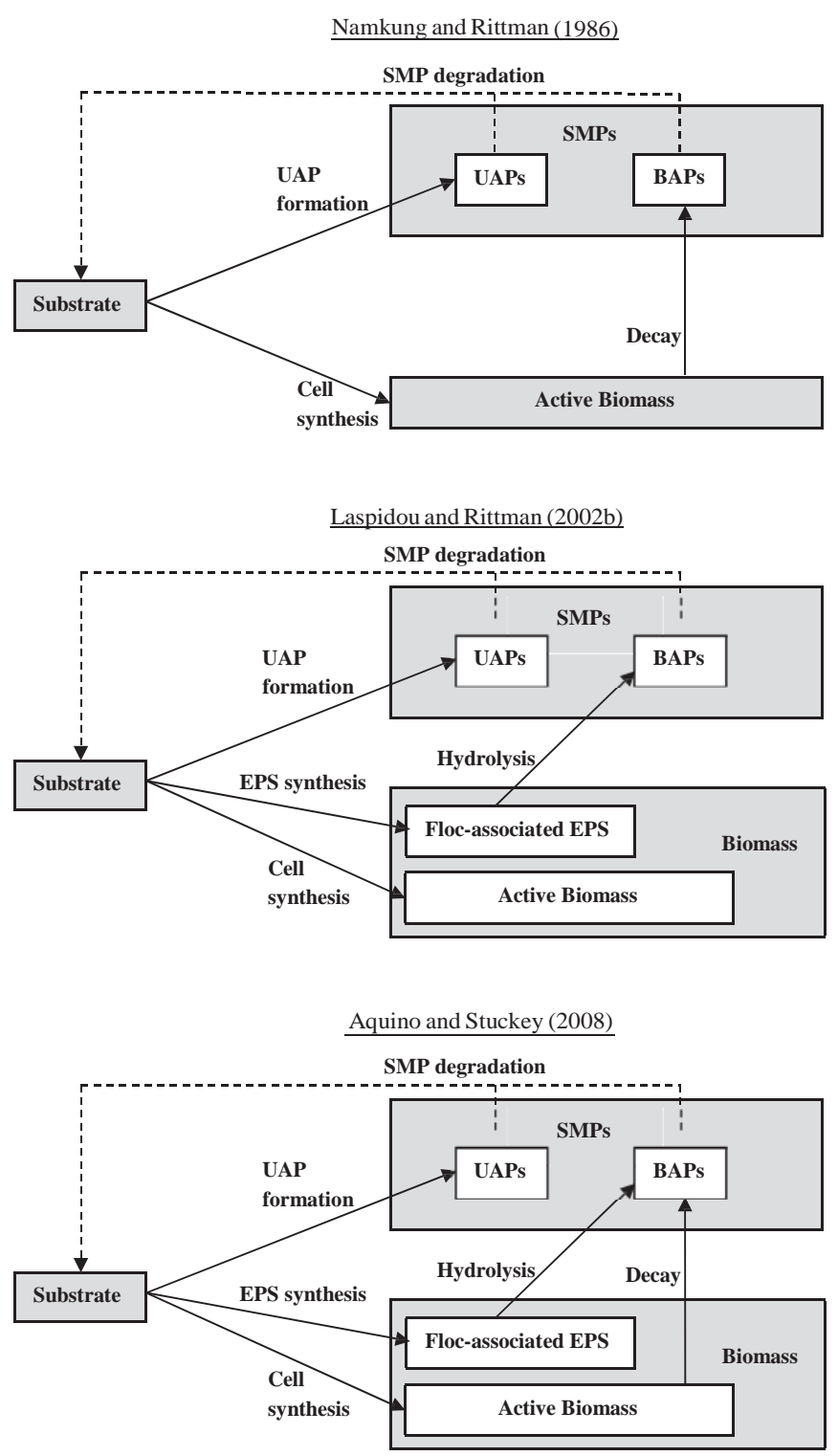

Fig. 1. Different concepts of the formation and degradation of SMPs used in typical modelling studies (modified after Menniti and Morgenroth, 2010).

de Silva and Rittmann (2000) or Laspidou and Rittmann (2002a) inherently emphasizes one mechanism over another and therefore, the models are not flexible enough particularly to capture the dynamic changes of the bound EPS to BAP. The Aquino and Stuckey (2008) model, being somewhat a combined version of the previous two models, was flexible enough to predict the dynamic changes in bound EPS and SMP production. The SMP produced by the erosion of bound EPS was found to be readily degradable while SMP produced by predation or biomass decay was slowly degradable. The findings of the biodegradability specific for the MBR system showed that the slowly biodegradable SMP produced by the biomass decay is the fraction with the highest concentration. Thus, it was concluded in the study that the inclusion of the SMP production mechanism from the biomass decay is significant to capture the SMP kinetics over a wide range of the MBR operating conditionsi.e.SRT.

In a recent review Fenu et al. (2010) mentioned that neglecting one of the two SMP fractions could lead to simplification of the mathematical model at least by reducing the number of state variables. The operating and environmental conditions of a wastewater 
treatment system e.g. the SRT of the MBR system may determine the predominant fraction case by case for the different process specific conditions. However, the ASM based hybrid models in the early nineties used to consider only BAP fractions regardless of the process specific conditions. It was also reported in the paper that the BAP fractions typically dominate over the UAPs at reasonably high SRTs (Furumai and Rittmann, 1992) or in steady-state conditions (Aquino and Stuckey, 2008). The UAP was reported to predominate when the rate of substrate degradation is high (Laspidou and Rittmann, 2002a,b; Aquino and Stuckey, 2008). When the simplification of SMP modelling is sought under a process specific conditions of the MBR, one of the two SMP fractions can be assumed to play dominant role for the membrane fouling predictions. Recently, the UAP/BAP ratio has been suggested a new filterability index for the submerged MBR system (Gholikandi and Khosravi, 2012).

\section{Process parameters of MBR affecting SMP}

The effect of various process parameters on the production, accumulation and elimination of SMP associated with multiple and complex interactions between ambient operating conditions of MBR and SMP is still a major concern for the researchers in this field. Drews (2010) and Meng et al. (2009) discussed the effects of various operational parameters on the kinetics of SMPs in details. Among the operational parameters, the SRT has been identified as the main influential parameter for SMP concentration (inter alia Cho et al., 2003; Liang et al., 2007; Zarragoitia-Gonzalez et al., 2008; Jiang et al., 2008; Mannina and Di Bella, 2012). The SMP concentration were observed to drop at higher SRT which can be correlated with the less fouling propensity observed at higher SRT (Drews, 2010). Liang et al. (2007) observed that the accumulation of SMP in the MBR sounded out more at short SRTs (10 and 20 days) than the same at longer SRT (40 days). In contrast, Trussell et al. (2006) found that SMP contributed to the increase of the total filtration resistance with increasing SRT from 2 to 10days. Although the total EPS extracted was approximately the same for the two SRTs (10 day, 30 day) under the same organic loading rate in a study by Zhang et al. (2006), the soluble PS in the sludge suspension was about $100 \%$ higher for the SRT of 10 day than that for 30 day. Rosenberger et al. (2006) also found that the PS concentration was higher at an SRT of 8 day than that at an SRT of 15 day.

Among other factors, toxic compounds and hydrodynamics (or shear stress), and the availability of oxygen sources and the presence of nitrifying products can also play roles in SMP elimination, rejection and fouling propensity (Drews, 2010). Drews et al. (2007) observed lower SMP elimination at low DO concentration where sudden temperature changes led to spontaneous SMP release and increase in fouling rates. It was suggested in their study that a sufficient supply of oxygen should be maintained within the bioreactor and sudden temperature change should be avoided to achieve low SMP concentrations.

\section{State-of-the-art models for SMP kinetics}

In many MBR studies, SMPs have been admitted as one of the membrane founlants or as indirect indicators of fouling propensity (inter alia Rosenberger et al., 2005, 2006; Le-Clech et al., 2006; Wu et al., 2007; de la Torre et al., 2010; Fenu et al., 2010). Therefore, the overall efficiency of the treatment system cannot be evaluated by the mathematical modelling studies unless the SMP kinetics is included in the model. In the conventional ASM based hybrid models, the extension/modification by SMP concepts were done to pursue the following modelling objectives: (i) linking biology with fouling, (ii) soluble COD predictions (iii) model high SRT processes (Fenu et al., 2010). The early ASM-SMP hybrid models are termed in this paper as bioprocess models since the modelling objective was actually to capture the influences of the SMP on the systems' bioprocesses. Later, the bioprocess models were linked to the physical sub-model through integrating the SMP component in the description of the physical membrane fouling models which is termed here as integrated model. The following sections are, therefore, discussed categorising them into bioprocess models and integrated models.

\subsection{Bioprocess models}

Furumai and Rittmann (1992) presented a model to account for the formation and exchange of SMPs between heterotrophs and nitrifiers. Separate formation rates for the two types of SMP are presented in the model, the UAPs are produced in a rate proportional to the substrate utilization while the rate of BAPs' production is assumed to be proportional to the amount of active biomass. Both the heterotrophs and nitrifiers are considered for the production of SMPs but only heterotrophs degrade them for cell synthesis. The model was later modified to include specific features of the MBR processes by de Silva et al., 1998 and Urbain et al., 1998 (Ng and Kim, 2007). The main modifications were the elimination of biomass output in the effluent and partial removal of BAPs of larger macromolecules by the membrane. Additionally, denitrification reactions and separate consumption rates for UAPs and BAPs (according to the findings of Noguera et al., 1994) were also included in the modified model. The modified model contains 10 non-steadystate mass balance equations to characterize heterotrophs, nitrifiers, inert biomass, soluble COD, ammonia and nitrate nitrogen, nitrogen gas, oxygen, UAP and BAP.

Urbain et al. (1998) verified the simulations of the modified model against the observed results of a pilot-scale MBR plant in Aubergenville, France. Both the simulations and experimental results showed good correspondence in COD and nutrient removal, sludge production and biomass distribution under both the steadystate and transient conditions. In a similar study of de Silva et al. (1998), the model was able to predict accurately the sludge concentration and nitrogen species, and also to capture the trends for soluble effluent COD. However, the model was reported unable to handle the technical problems or sudden variations in the wastewater composition. The kinetic and stoichiometric parameters for the model were used as default values from literature and no fitting was performed for the calibration of the model.

Lu et al. (2001) first modified ASM1 (Henze et al., 1987) to include the kinetics of SMP. In the modified ASM1 model, UAP is produced directly by original substrate metabolism, and the soluble biodegradable organic matters derived from the biomass decay and the hydrolysis products of particulate biodegradable organic matters are classified as BAPs. Both UAP and BAP can be reused by heterotrophs for their growth according to the multiplicative Monod expression. The model presented 12 transient mass balance equations but excluded the effects of alkalinity. In their study, the model was validated against the observed results of a single completely mixed MBR system fed with synthetic wastewater under intermittent aerobic condition. Although the simulation results were in good agreement with the experimental data, the model was questioned of COD and charge imbalances (Jiang et al., 2008).

Ahn et al. (2006) integrated a unified theory into ASM1 where BAPs are uniquely derived from hydrolysis of the EPS. The model is over parameterized as it has introduced additionally 2 components, 5 processes and 8 parameters. The model was verified for the characterization of the MBR sludge at different SRTs. The simulation results showed good correspondence with the experimental values but no effect of SRT was found on SMP production.

Jiang et al. (2008) proposed an ASM2d-SMP hybrid model which is more efficient to identify the fate of different fractions of SMP. 
Although the calibration protocol of the model is well defined, there is considerable increase in the total number of equations and model parameters as well. However, the research community has not yet reached a general consensus about the methods of characterization of the SMP fractions. Jiang et al. (2008) set up specific batch tests in a lab-scale MBR in order to evaluate separately the SMP related parameters. Production, hydrolysis and degradation were the three steps considered in their study of the complete BAP kinetics. However hydrolysis was confirmed as the first step for SMP utilization as both the UAP and BAP typically exhibited the biodegradability and had a large fraction of $\mathrm{MW}$ greater than 20 kDa (Tian et al., 2011). SMP kinetics was integrated with ASM3 by the latter authors, and it was reported that the SRT was the key parameter controlling the SMP concentration. As proposed by Tian et al. (2011), the kinetics of the formation and degradation of the UAP and BAP are given in Eqs. (1)e(4). However, the kinetics of the UAP formation (Eq. (1)) is much more complicated compared to the model equation of the same given by the other researchers. A list of equations of the formation and degradation kinetics of UAP and BAP as proposed by different researchers can be found in another review paper by Zuthi et al. (2012).

UAP formation rate:

$$
\begin{aligned}
r_{\mathrm{UAP}}= & \gamma_{\mathrm{UAP}, \mathrm{H}} \frac{S_{\mathrm{NH}}}{S_{\mathrm{NH}}+K_{\mathrm{NH}, \mathrm{H}}} \frac{S_{\mathrm{O}}}{S_{\mathrm{O}}+K_{\mathrm{OH}}} \\
& \times\left(\mu_{\mathrm{H}, \mathrm{STO}} \frac{K_{\mathrm{S}}}{K_{\mathrm{S}}+S_{\mathrm{S}}} \frac{X_{\mathrm{STO}} / X_{\mathrm{H}}}{\left(X_{\mathrm{STO}} / X_{\mathrm{H}}\right)+K_{\mathrm{STO}}}+\mu_{\mathrm{H}, \mathrm{S}} \frac{S_{\mathrm{S}}}{K_{\mathrm{S}}+S_{\mathrm{S}}}\right) X_{\mathrm{H}}
\end{aligned}
$$

UAP hydrolysis rate:

$r_{\mathrm{h}, \mathrm{UAP}}=k_{\mathrm{h}, \mathrm{UAP}} \frac{S_{\mathrm{UAP}}}{S_{\mathrm{UAP}}+K_{\mathrm{UAP}}} \frac{S_{\mathrm{o}}}{S_{\mathrm{o}}+K_{\mathrm{OH}}} X_{\mathrm{H}}$

BAP formation rate:

$r_{\mathrm{BAP}}=f_{\mathrm{BAP}}\left(b_{\mathrm{STO}} X_{\mathrm{STO}}+b_{\mathrm{A}} X_{\mathrm{A}}+b_{\mathrm{H}} X_{\mathrm{H}}\right)$

BAP hydrolysis rate:

$r_{\mathrm{h}, \mathrm{BAP}}=k_{\mathrm{h}, \mathrm{BAP}} \frac{S_{\mathrm{BAP}}}{S_{\mathrm{BAP}}+K_{\mathrm{BAP}}} \frac{S_{\mathrm{O}}}{S_{\mathrm{O}}+K_{\mathrm{OH}}} X_{\mathrm{H}}$

Based on the findings of the simulation results of the model for a full-scale MBR, Fenu et al. (2011) proposed some modifications of the ASM2d-SMP hybrid model of Jiang et al. (2008). The modifications were made by introducing heterotrophic sludge yield as $\mathrm{Y}_{\mathrm{H}}\left(1-\mathrm{f}_{\mathrm{UAP}}\right)$, excluding autotrophic biomass in the UAPs formation, and assuming that the degradation of UAP and BAP produced intermediate products and biomass but not the new BAP or UAP. However the model description was limited for the modelling of the bioprocesses only without any correlation of the SMP with the physical membrane fouling phenomena.

Oliveira-Esquerre et al. (2006) presented the ASM3-MP model based on ASM3 (Gujer et al., 1999) but introduced in the model a new state variable termed as MP (microbial products). The UAP and BAP were lumped into a general term MP for which only the decay products of the biomass was considered. The modified ASM3-MP model was unable to predict the measured SMP concentrations without compromising the prediction accuracy of original ASM3 state variables.

\subsection{Integrated models}

In order to capture all the distinct characteristics of MBR, the bioprocess model has been linked to the physical sub-model or membrane fouling model in few studies (Lee et al., 2002; Zarragoitia-Gonzalez et al., 2008; Di Bella et al., 2008; Mannina et al., 2011). Lee et al. (2002) developed a model for SMBR by coupling an ASM1-SMP hybrid model with a conventional resistance-in-series model. Four additional processes are presented in the model for describing fate of SMP while the process rates and stoichiometry for the carbon and nitrogen are kept the same as ASM1. All the UAP but only a portion of BAP is considered to be biodegradable in the model. The membrane fouling in the model is captured by the conventional resistance-in-series model which has its components derived from the bioprocess sub-model. Although the contribution of the SMP is considered for its influence on the specific resistance, its contribution is ignored in total cake mass deposited on the membrane.

Jang et al. (2006) developed a model based on the unified theory (Laspidou and Rittmann, 2002b) for the production and degradation of EPS and SMP. The model was extended with several additional equations using the modified fouling index ( $\left.\mathrm{MFI}_{\mathrm{MBR}}\right)$ of the MBR aimed to predict the biofouling potentials caused by soluble and suspended solids (Eq. (5)). Therefore, the $\mathrm{MFI}_{\mathrm{MBR}}$ in the model was divided into soluble materials (MFIsol) and suspended solids (MFIss) and was measured by Eqs. (6) and (7) respectively.

$$
\begin{aligned}
& \mathrm{MFI}_{\mathrm{MBR}}=\mathrm{MFI}_{\mathrm{Sol}}+\mathrm{MFI}_{\mathrm{SS}} \\
& \mathrm{MFI}_{\mathrm{Sol}}=\beta\left[\mathrm{S}\left(1-f_{\mathrm{S}}\right)+\mathrm{BAP}\left(1-f_{\mathrm{BAP}}\right)+\mathrm{UAP}\left(1-f_{\mathrm{UAP}}\right)\right] \\
& \mathrm{MFI}_{\mathrm{SS}}=\gamma \frac{\mathrm{QS}_{\mathrm{i}}}{V\left(X_{\mathrm{a}}+\mathrm{EPS}\right)}
\end{aligned}
$$

The simulation results showed that the MFI $_{\text {Sol }}$ contributed more to biofouling of MBR than the MFIss except for a SRT of less than 5 days. The model is over parameterized and it has yet to be validated by the observed results of the full-scale MBR p lants.

Zarragoitia-Gonzalez et al. (2008) presented a hybrid model linking part of an ASM1-SMP hybrid model (Lu et al., 2001) and a membrane fouling model. Only heterotrophs were considered in the model. Although biomass decay was considered for the BAP production, the SMP concentration was used to calculate bound EPS as $\mathrm{S}_{\mathrm{UAP}} \mathrm{p} \mathrm{S}_{\mathrm{BAP}} / 0.8 \mathrm{X}_{\mathrm{TSS}}$. Considering the usual operating condition of an MBR, the use of model was limited to aerobic condition only. As the model was based on Lu's model, the model predicted an incomplete and incorrect COD balance. Although the model contains high number of SMP parameters, it neglects some important physical mechanisms and phenomena, such as the dynamic deepbed filtration of cake layer and their possible influence on the removal of organics (Mannina et al., 2011).

Another adoption of the biological mechanism Lu's model was by Di Bella et al. (2008) and it was connected to the physical mechanism of membrane for the removal of organics. The formation of the cake layer on membrane was described according to the $\mathrm{Li}$ and Wang (2006) model. In addition, COD removal by the cake layer and the physical membrane were quantified in the model. The model was calibrated well and could predict the COD better than the previous models of its kind. However, the SMP concentration was missing in the work. The complexity of the model calibration was reduced by the calibration using the most sensitive parameters only. Di Bella et al. (2008) carried out about 10,000 Monte Carlo simulations for the calibration of the model followed by the calibration by trial and error in order to define the values of the most sensitive parameters of the model. It was found in the sensitivity test that the $\mathrm{Y}_{\mathrm{SMP}}$ and $\mathrm{g}_{\mathrm{UAP}, \mathrm{A}}$ had strong influence on the majority of output variables while $b_{B A P, h}$ and $m_{S M P}$ had mainly affected the parameters $\mathrm{NH}_{4}$ and $\mathrm{NO}_{3}$. According to Mannina et al. (2011), the major limitations of the model were that the different effects of 
aeration on the cake deposition was not taken into account in the model, and the filtration were considered uniformly distributed on the entire surface of the membrane which was impractical especially in case of hollow fibre membrane in submerged configuration.

In order to overcome the above limitations of the above model (Di Bella et al., 2008), a few modifications were proposed by Mannina et al. (2011) e.g. the kinetics of the SMP formation and degradation (according to Jiang et al., 2008), the dynamic phenomena of the attachment and detachment of the cake layer on the membrane and their influence of the development of fouling, the variation of the transmembrane pressure (TMP) and the variation of the membrane resistance due to fouling. An innovative calibration protocol based on step-wise approach followed by preliminary global sensitivity analysis was employed to calibrate the model. In the new model, the biological process was based on a modified version of the modelling approach proposed by Jiang et al. (2008) which was linked with the sectional resistance-in-series model for modelling the physical mechanisms of the membrane. From the results of the sensitivity tests, it was reported that $Y_{a}, f_{S i}$ and $f_{B A P}$ influenced COD in the reactor while the $\mathrm{i}_{\mathrm{x}, \mathrm{p}}$ is influential on the $\mathrm{NH}_{4}$ concentration in the permeate. Like the earlier models, SMP concentration was also missing in the work but the model predicted well the MLSS, $\mathrm{COD}_{\text {perm }}, \mathrm{NO}_{3}$ and $\mathrm{R}_{\text {tot }}$ during the long-term behaviour of the treatment system. The simulations showed discrepancy in some cases which was ascribed to the poor experimental investigation during the first days of start-up period and also to the initial inoculum biomass acclimatization that was not modelled.

In a study to find out the influences of start-up strategies on MBR performance and fouling development of membrane fouling, Mannina and Di Bella (2012) applied the model developed by Jiang et al. (2008) in order to assess different fouling rate. Mannina and Di Bella (2012) monitored an MBR pilot plant for two experimental periods, each of 65 days, and within this time the plant was started up with (period 1) and without (period 2) of inoculation of biomass. Higher net SMP production during the start-up period with sludge inoculation was observed compared to the period without sludge inoculation. The finding was attributed to the increased biological activity in the experimental period 2 because of the different SRT. However the stickiness of the biomass particles in the period 1 was slightly higher than that in period 2 which was assumed due to the high SMP concentration in the initial phase of start-up without inoculation. Also assuming that the SMPs can be changed by the biological and physical actions which can be retained at a different proportion inside the cake layer, three different SMP concentrations were calculated at the different MBR sections: reactor $\left(\mathrm{SMP}_{\text {reactor}}\right)$, cake layeremembrane interface (SMP $\left.\mathrm{S}_{\text {cake-mem }}\right)$ and permeate $\left(\mathrm{SMP}_{\text {permeate}}\right)$. The results of the model simulation (Mannina and Di Bella, 2012) confirmed the complex relationship between MLSS and SMP formation-degradation especially during the start-up phase. Lower concentration of SMPs was found in period 1 due to higher SRT. However, higher specific SMP concentration was observed during the first 25 days of plant operation in period 1 which might be due to the variations in operational conditions i.e. F/M and MLSS.

\section{Summary and outlook}

It is evident from the review presented in the paper that the extension of the ASMs with the kinetics of SMP modelling has made some hybrid models too complicated to be applied in practical applications for the full-scale MBR plants. The integration of the membrane fouling phenomena in the ASM-SMP hybrid models has made the task much more challenging. Some integrated mathematical models are over parameterized and consequently the calibration of the models followed by the sensitivity analyses is also a tedious procedure. However, attention should be paid on the strategies to reduce the model parameters without significant compromise in the accuracy of the model predictions. Based on the comparative studies on several published ASM-SMP models and integrated models, it is recommended that an integrated model by combining a modified ASM1-SMP model (Lu et al., 2001) with the membrane's sectional-resistance approach (Zarragoitia-Gonzalez et al., 2008; Mannina et al., 2011) would describe the bioprocess of the MBR and membrane fouling with a reasonable degree of accuracy. The equations and the value of kinetic and stoichiometric parameters of the proposed model are shown in Tables 1 and 2.

The SMP fractions produced by the biological system may differ among different MBRs for their process specific conditions. The differences may be not only in quantity but also in quality with associated effects of both criteria on the membrane fouling. This obviously demands appropriate characterization of the SMP fractions e.g., into BAP and UAP. However, there is no general consensus about the most appropriate methods for the characterization of SMP fractions. In this backdrop, the $\mathrm{S}_{\mathrm{SMP}}$ is introduced in the model as a lumped parameter which, in fact, would account for the aerobic and anoxic growth of dominant fraction of SMPs (BAPs) by the heterotrophic organisms $\left(\mathrm{X}_{\mathrm{B}, \mathrm{H}}\right)$. The parameter, $\mathrm{S}_{\mathrm{SMP}}$, is introduced in both the biological and physical sub-model.

A specific modification in the model is recommended in order to incorporate terms of alkalinity to capture the continuity in ionic charge of the biological processes. This may eliminate the problems of charge imbalance of the Lu's model, and hence the model is able to predict possible changes of $\mathrm{pH}$ (Hauduc et al., 2010) due to changes in environmental and operating conditions. The major limitation of the Lu's model for COD imbalance can be eliminated if the COD removal by the membrane and also by the cake layer of the membrane in considered. For a continuously or intermittently aerated MBR system, the biological growth is not only dependent

Table 1

Suggested expressions for integrated mathematical modelling of SMPs in MBR.

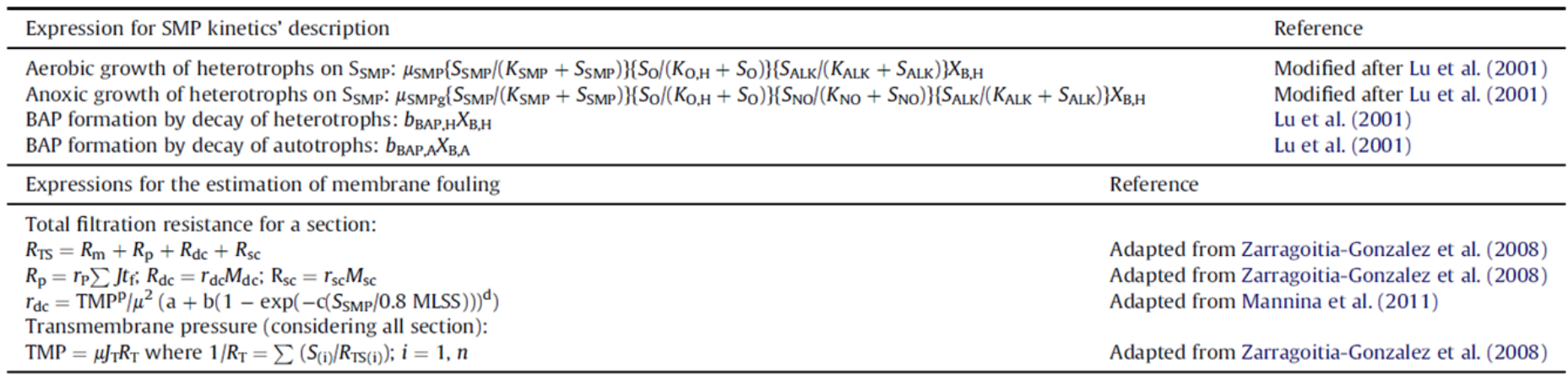


Table 2

Typical values of SMP-relevant parameters of the suggested model.

\begin{tabular}{llc}
\hline Parameters & Unit & Value $^{* *}$ \\
\hline$Y_{\mathrm{SMP}}$ & ${\text { g cell COD formed (g COD oxidized })^{-1}}$ & 0.5 \\
$\mu_{\mathrm{SMP}}$ & day $^{-1}$ & 0.7 \\
$b_{\mathrm{BAP}, \mathrm{H}}$ & day $^{-1}$ & 0.4 \\
$\mathrm{~b}_{\mathrm{BAP}, \mathrm{A}}$ & day $^{-1}$ & 0.1 \\
$K_{\mathrm{SMP}}$ & $\mathrm{gCOD} \mathrm{m}^{-3}$ & 30 \\
$\gamma_{\mathrm{UAP}, \mathrm{H}}$ & - & 0.38 \\
$\gamma_{\mathrm{UAP}, \mathrm{A}}$ & - & 1.56 \\
\hline
\end{tabular}

** Source: Lu et al. (2001)

on the carb on substrate but also on the oxygen supplied by the aeration (Gehlert and Hapke, 2002). The consideration of the aeration phenomena can also reduce the overall problem of the COD imbalance of the model.

\section{Conclusions}

The production and degradation of SMP within an MBR can be greatly influenced by the operational specificities of the treatment process such as the longer SRT with reduced concentration of SMP. The effects of feeding ratios along with the concentration of the total suspended solids, MLSS etc. within the bioreactor can also play a dominant role. The proposed model inherently considers that the non-biodegradable SMP from cell lysis becomes a portion of the inert COD in the effluent and hence can influence the effluent quality. The SMP retained due to smaller pore sizes of the membrane and also that retained within the cake layer on the membrane can be considered within the framework of the proposed semi-empirical integrated model.

The model is not over-parameterized as it includes only 4 additional equations to ASM1 without significant increase of the SMP related parameters. However, the model is required to be validated against number of batch test results both at lab-scale and full-scale MBRs over a wide range of SRT and feeding ratios. The effects of the biological parameters such as SSMP and MLSS on the membrane resistance and fouling need to investigated. The simplified modelling approach would be useful to establish relationships between the biological kinetics of SMP and the membrane fouling. This can help optimizing operating parameters of an MBR for better effluent quality with controlled membrane fouling.

\section{References}

Ahn, Y., Choi, Y., Jeong, H., Chae, S., Shin, H.S., 2006. Modeling of extracellular polymeric substances and soluble microbial products production in a submerged membrane bioreactor at various SRTs. Water Science and Technology 53, $209 e 216$.

Aquino, S.F., Stuckey, D.C., 2008. Integrated model of the production of soluble microbial products (SMP) and extracellular polymeric substances (EPS) in anaerobic chemostats during transient conditions. Biochemical Engineering Journal 38, $138 \mathrm{e} 146$.

Cho, J., Ahn, K.-H., Seo, Y., Lee, Y., 2003. Modification of ASM1 for a submerged membrane bioreactor system: including the effects of soluble microbial products on membrane fouling. Water Science and Technology 47, 177e181.

de la Torre, T., Iversen, V., Meng, F., Stuber, J., Drews, A., Lesjean, B., Kraume, M., 2010. Searching for a universal fouling indicator for membrane bioreactors. Desalination and Water Treatment 18, $264 \mathrm{e} 269$.

de Silva, D.G.V., Rittmann, B.E., 2000. Nonsteady-state modeling of multispecies activated-sludge processes. Water Environment Research 72, 554e565.

de Silva, D.G.V., Urbain, V., Abeysinghe, D.H., Rittmann, B.E., 1998. Advanced analysis of membrane bioreactor performance with aerobic-anoxic cycling. Water Science and Technology 38, 505e512.

Di Bella, G., Mannina, G., Viviani, G., 2008. An integrated model for physicalbiological wastewater organic removal in a sMBR: model development and parameter estimation. Journal of Membrane Science 322, 1 e12.

Drews, A., 2010. Membrane fouling in membrane bioreactors-characterisation, contradictions, cause and cures. Journal of Membrane Science 363, 1e28.

Drews, A., Mante, J., Iversen, V., Vocks, M., Lesjean, B., Kraume, M., 2007. Impact of ambient conditions on SMP elimination and rejection in MBRs. Water Research 41, $3850 e 3858$.
Drews, A., Vocks, M., Bracklow, U., Iversen, V., Kraume, M., 2008. Does fouling in MBRs depend on SMP? Desalination 231, 141e149.

Fenu, A., Guglielmi, G., Jimenez, J., Sperandio, M., Saroj, D., Lesjean, B., Brepols, C., Thoeye, C., Nopens, I., 2010. Activated sludge model (ASM) based modelling of membrane bioreactor (MBR) processes: a critical review with special regard to MBR specificities. Water Research 44, 4272e4294.

Fenu, A., Wambecq, T., Thoeye, C., De Gueldre, G., Van de Steene, B., 2011. Modelling soluble microbial products (SMPs) in a dynamic environment. Desalination and Water Treatment 29, 210e217.

Furumai, H., Rittmann, B.E., 1992. Advanced modelling of mixed population of heterotrophs and nitrifiers. Water Science and Technology 26, 493e502.

Gehlert, G., Hapke, J., 2002. Mathematical modeling of a continuous aerobic membrane bioreactor for the treatment of different kinds of wastewater. Desalination 146, 405e412.

Gholikandi, G.B., Khosravi, M., 2012. Upgrading of submerged membrane bioreactor operation with regard to soluble microbial products and mathematical modeling for optimisation of critical flux. Desalination and Water Treatment 39, $199 \mathrm{e} 208$.

Gujer, W., Henze, M., Mino, T., van Loosdrecht, M., 1999. Activated sludge model no. 3. Water Science and Technology 39, $183 e 193$.

Hauduc, H., Rieger, L., Takacs, I., Heduit, A., Vanrolleghem, P.A., Gillot, S., 2010. A systematic approach for model verification: application on seven published activated sludge models. Water Science and Technology 61, 825e839.

Henze, M., Grady, C.P.L.J., Gujer, W., Marais, G.v.R., Matsuo, T., 1987. Activated Sludge Model No. 1. IAWPRC Scientific and Technical Report No. 1. IAWPRC, London.

Jang, N., Ren, X., Cho, J., Kim, I.S., 2006. Steady-state modeling of bio-fouling potentials with respect to the biological kinetics in the sMBR. Journal of Membrane Science 284, 352e360.

Jiang, T., Myngheer, S., Pauw, D.J.D., Spanjers, H., Nopens, I., Kennedy, M.D., Amy, G., Vanrolleghem, P.A., 2008. Modelling the production and degradation of soluble microbial products (SMP) in membrane bioreactors (MBR). Water Research 42, $4955 \mathrm{e} 4964$.

Kimura, K., Naruse, T., Watanabe, Y., 2009. Changes in characteristics of soluble microbial products in membrane bioreactors associated with different solid retention times: relation to membrane fouling. Water Research 43, 1033 e1039.

Laspidou, C.S., Rittmann, B.E., 2002a. Non-steady state modeling of EPS, SMPs, and active and inert biomass. Water Research 36, 1983e1992.

Laspidou, C.S., Rittmann, B.E., 2002b. A unified theory for EPS, SMPs, and active and inert biomass. Water Research 36, 2711e2720.

Le-Clech, P., Chen, V., Fane, T.A.G., 2006. Fouling in membrane bioreactors used in wastewater treatment. Journal of Membrane Science 284, 17 e53.

Lee, Y., Cho, J., Seo, Y., Lee, J.W., Ahn, K.-H., 2002. Modelling of submerged membrane bioreactor process for wastewater treatment. Desalination 146, $451 \mathrm{e} 457$.

Li, X., Wang, X., 2006. Modelling of membrane fouling in a submerged membrane bioreactor. Journal of Membrane Science 278, 151e161.

Liang, S., Liu, C., Song, L., 2007. Soluble microbial products in membrane bioreactor operation: behaviors, characteristics, and fouling potential. Water Research 41, $95 \mathrm{e} 101$.

Lu, S.G., Imai, T., Ukita, M., Sekine, M., Higuchi, T., Fukagawa, M., 2001. A model for membrane bioreactor process based on the concept of formation and degradation of soluble microbial products. Water Research 35, 2038 e2048.

Mannina, G., Di Bella, G., 2012. Comparing two start-up strategies for MBRs: experimental study and mathematical modelling. Biochemical Engineering Journal 68, 91e103.

Mannina, G., Di Bella, G., Viviani, G., 2011. An integrated model for biological and physical process simulation in membrane bioreactors (MBRs). Journal of Membrane Science 376, $56 e 69$.

Meng, F., Chae, S., Drews, A., Kraume, M., Shin, H., Yang, F., 2009. Recent advances in membrane bioreactors (MBRs): membrane fouling and membrane material. Water Research 43, 1489e1512.

Menniti, A., Morgenroth, E., 2010. Mechanisms of SMP production in membrane bioreactors: choosing an appropriate mathematical model structure. Water Research 44, 5240e5251.

Namkung, E., Rittmann, B.E., 1986. Soluble microbial products (SMP) formation kinetics by biofilms. Water Research 20, 795e806.

Ng, A.N.L., Kim, A.S., 2007. A mini-review of modeling studies on membrane bioreactor (MBR) treatment for municipal wastewaters. Desalination 212, $261 \mathrm{e} 281$.

Noguera, D.R., Araki, N., Rittmann, B.E., 1994. Soluble microbial products (SMP) in anaerobic chemostats. Biotechnology and Bioengineering 44, 1040e1047.

Oliveira-Esquerre, K., Narita, H., Yamato, N., Funamizu, N., Watanabe, Y., 2006. Incorporation of the concept of microbial product formation into ASM3 and the modelling of a membrane bioreactor for wastewater treatment. Brazilian Journal of Chemical Engineering 23, 461e471.

Ramesh, A., Duu-Jong, L., Hong, S.G., 2006. Soluble microbial products (SMP) and soluble extracellular polymeric substances (EPS) from wastewater sludge. Environmental Biotechnology 73, $219 \mathrm{e} 225$.

Rosenberger, S., Evenblij, H., Poele te, S., Wintgens, T., Laabs, C., 2005. The importance of liquid phase analyses to understand fouling in membrane assisted activated sludge processed six case studies of different European research groups. Journal of Membrane Science 263, $113 e 126$.

Rosenberger, S., Laabs, C., Lesjean, B., Gnirss, R., Amy, G., Jekel, M., Schrotter, J.C., 2006. Impact of colloidal and soluble organic material on membrane performance in membrane bioreactors for municipal wastewater treatment. Water Research 40, 710e720. 
Tian, Y., Chen, L., Jiang, T., 2011. Characterization and modeling of the soluble microbial products in membrane bioreactor. Separation and Purification Technology 76, 316e324.

Trussell, R.S., Merlo, R.P., Hermanowicz, S.W., Jenkins, D., 2006. The effect of organi loading on process performance and membrane fouling in a submerged membrane bioreactor treating municipal wastewater. Water Research 40, $2675 e 2683$.

Urbain, V., Mobarry, B., de Silva, V., Stahl, D.A., Rittmann, B.E., Manem, J., 1998 Integration of performance, molecular biology and modeling to describe the activated sludge process. Water Science and Technology 37, $223 e 229$.

Wu, Z., Wang, Z., Zhou, Z., Yu, G., Gu, G., 2007. Sludge rheological and physiological characteristics in a pilot-scale submerged membrane bioreactor. Desalination 212, $152 \mathrm{e} 164$.
Xie, W., Ni, B., Seviour, T., Sheng, G., Yu, H., 2012. Characterization of autotrophic and heterotrophic soluble microbial product (SMP) fractions from activated sludge. Water Research 46, 6210e6217.

Zarragoitia-Gonzalez, A., Schetrite, S., Alliet, M., Jauregui-Haza, U., Albasi, C., 2008. Modeling of SMBRs: conceptual study about link between activated sludge biokinetics, aeration and fouling process. Journal of Membrane Science 325, $612 \mathrm{e} 625$.

Zhang, J.S., Chuan, C.H., Zhou, J.T., Fane, A.G., 2006. Effect of sludge retention time on membrane bio-fouling intensity in a submerged membrane bioreactor. Separation Science and Technology 41, 1313e1329.

Zuthi, M.F.R., Ngo, H.H., Guo, W.S., 2012. Modelling bioprocesses and membrane fouling in membrane bioreactor (MBR): a review towards finding an integrated model framework. Bioresource Technology 122, 119e129. 